\title{
INTRODUCTION: CONTINUING LEGACIES: ENGAGING CUSTODIANS IN HERITAGE CONSERVATION
}

\author{
Rahimah Abdul Aziz ${ }^{1 *}$, Ong Puay Liu², Sarah Aziz ${ }^{3}$ and Sharina Abdul Halim ${ }^{3}$ \\ ${ }^{1}$ School for Social, Development and Environmental Studies, \\ ${ }^{2}$ Institute for Ethnic Studies (KITA), \\ ${ }^{3}$ Institute for Environment and Development (LESTARI), Universiti Kebangsaan \\ Malaysia, MALAYSIA \\ *Corresponding author: ikra@ukm.edu.my
}

Published online: 29 December 2017

To cite this article: Rahimah Abdul Aziz, Ong Puay Liu, Sarah Aziz and Sharina Abdul Halim. 2017. Introduction: Continuing legacies: Engaging custodians in heritage conservation. Kajian Malaysia 35(Supp.1): 1-10. https://doi.org/10.21315/km2017.35.Supp.1.1

To link to this article: $\mathrm{https}: / /$ doi.org/10.21315/km2017.35.Supp.1.1

This special issue of Kajian Malaysia on "Continuing Legacies: Engaging Custodians in Heritage Conservation" with focus in Malaysia is to draw attention to the multi-dimensional aspects of continuing legacies and the role of custodians that cross-cut various disciplines. The issue presents a collection of nine refereed research articles. They are written by a group of researchers from various disciplines and background of Faculties and Research Institutes at Universiti Kebangsaan Malaysia. Seven of the papers are written by the Governance and Education for Heritage Conservation Research Group members based on findings of their various research on the subject, while two papers are written by colleagues from other research groups but who are also focusing on heritage conservation. This is to emphasise that the success of heritage conservation requires multidisciplinary efforts and that heritage conservation should be a concern of all. It also underlines the fact that the success of any heritage conservation efforts depend on the combination of top-down, bottom-up grassroots approach.

\section{HERITAGE CONSERVATION FOR CONTINUING LEGACIES}

UNESCO's support for World Heritage Sites, Man and Biosphere Reserves, as well as Global Geoparks is a response to the call from many countries for an international framework to enhance the value of the Earth's heritage. This includes all of Earth's natural and cultural resources. This support is based on the outstanding universal human values (OUHVs) that the World Heritage Sites, Man 
and Biosphere Reserves and Global Geoparks possess. Langkawi islands, Melaka and Georgetown possess unique OUHVs that have led to their recognition by UNESCO as sites to be conserved and protected.

In Malaysia there are conservation sites that are recognised under World Heritage Sites, Man and Biosphere Reserves, and Global Geoparks. For example Langkawi islands was conferred the Global Geopark status in 2007, while Melaka and Georgetown were conferred the status of World Heritage Sites in 2008 and Tasik Chini was designated as Man and Biosphere Reserves in 2009. Langkawi Global Geopark boasts of 550 million years of geological history and natural beauty. Melaka, on the other hand, has unique living multicultural heritage. Besides these, there are also other areas or sites that are yet to be discovered or recognised. The interactions between the humans and their natural environment underlie cultural heritage in Malaysia. The interactions have bequeathed the culture with aesthetic, unique and outstanding universal human values (OUHVs). As such, there has to be conscious efforts made to protect and conserve these OUHVs, so as to ensure their sustainability for generations to come.

The link between natural and cultural heritage as well as tangible and intangible heritage is intricate and intertwined. It transcends the object or subject of conservation, taking into account the need to balance multiple needs and demands of development, and the risks or threats that may lead to its loss or destruction. There are three fundamental questions that will have to be addressed, the first looks at the need to define or contextualise what requires safeguarding (Trinidad, 2015). The other is linked to determining custodianship, looking at how communities or persons acquire legitimacy from historical rights or even ownership (Jopela, 2011). This leads to the third question, looking at linking what needs to be safeguarded, to custodianship and the required measures, or at the very least options, to ensure the link between those who know and care, and those who hold the mandate are properly looked at.

Based on the three fundamental questions mentioned above, Malaysia, through its National Heritage Act 2005, has set a remit by which the conservation or preservation of what is deemed as heritage should abide. It sets out a provision to determine what can be considered as a heritage, with a checklist of nine points looking at factors such as historical importance; design characteristics; innovations or achievements; social or cultural associations; potential to educate or illustrate; importance in exhibiting richness or diversity; and rarity or uniqueness. Heritage under the Act is split into two main types, cultural and natural heritage. The Act interprets culture heritage to include tangible or intangible form of cultural property, structure or artefact and may include a heritage matter, object, item, artefact, formation structure, performance, dance, song, music that is pertinent to the historical or contemporary way of life of Malaysians, on or in land or underwater 
cultural heritage of tangible form but excluding natural heritage. Natural heritage is interpreted to include natural features of any area in Malaysia which may consist of earthly physical or biological formations or group of such formations, geological or physiographical features, mountains, rivers, streams, rock formation, sea shore or any natural sites of outstanding value from the point of view of nature, science, history conservation or natural beauty including flora and fauna of Malaysia.

This distinction indicates that what is deemed heritage goes beyond traditional disciplinary domains, as it connects both the human and nature, and at times the link between both heritages is intertwined that it is difficult to design a measure for conservation just to suit a particular type. In nature conservation for example, there has been a call to move from compartmentalised disciplines, shifting towards trans-disciplinarity, where collaboration and awareness play an important role to connect people with nature (Balmford and Cowling, 2006). This type of research calls for joint efforts that cross many disciplines to create new approaches, concepts, theoretical framework, and methodologies in order to address a common problem. In this case, it is about heritage conservation. Inputs are required from multiple disciplines otherwise this will lead to poor decisions and policies (Reyers et al. 2010 citing Daily and Ehrlich, 1999).

Where cultural heritage conservation is concerned, the International Council of Monuments and Sites (ICOMOS), in its 1987 Charter for the Conservation of Historic Towns and Urban Areas ("Washington Charter"), recognises that urban communities of today are the expression of a diversity of societies throughout history, and conservation plans must address all relevant factors that include archaeology, history, architecture, sociology and economics. It should also state the legal, administrative and financial measures necessary to attain the principal objective of the conservation plan (ICOMOS, 1987).

With regard to custodianship and heritage conservation, both natural and cultural, the question arises as to who is the "custodian"? The conventional approach is to equate custodian with a particular community or neighbourhood, which perceives the natural and/or cultural asset/property/feature as "heritage", or as having heritage value. However, for sustainable heritage conservation, custodian should encompass a wider framework of groups, communities and parties who have roles and responsibilities, not only in safeguarding and conserving the heritage, but also in communicating heritage. Hence, engaging custodians in heritage conservation for continuing legacies should be premised on a more inclusive platform, involving multiple stakeholders, as well as focusing not on products of concrete manifestations such as dances and songs (United Nations Educational, Scientific and Cultural Organization [UNESCO], n.d.), but rather on processes and conditions, on transferring of knowledge, skills and meaning from generation to generation (UNESCO, n.d.). 
There is a lot that will have to be done at a purposive level to better understand, enhance, and document the relevance of conservation plans to national values, engaging a whole range of processes that include assessment, planning, stakeholder engagement, value transfer and behaviour change (Reyers et al., 2010). Being engaged in a social process will require mutual learning, spanning relevant disciplines at all levels of the transdisciplinary hierarchy, requiring some parties to become listeners, understanding contexts and perspectives, earning basic trust, and appreciating that a common language exist, only then can knowledge produced at one disciplinary level be transformed to have meaning at another level resulting in co-produced new knowledge that truly transcends disciplines (Reyers et al., 2010).

Making the past present for the future is the underlying principle of this great effort to safeguard the sustainability of both the cultural and natural heritage. However, the success of heritage conservation greatly depends on the involvement and engagement of all custodians, both state and non-state actors, who are essentially the custodians of the various heritage sites to be found in the country. Only then could the heritage be handed down to future generations to continue their legacies. However, this has proven to be a challenge in light of the rapid development taking place in the country. Thus, "Continuing Legacies: Engaging Custodians in Heritage Conservation" deals with the complexities in the governance of heritage sites based on the concept of sustainability and conservation of heritage for the sake of the future generations.

\section{ENGAGING CUSTODIANS}

The issue begins with a broader stance regarding local community participation for heritage conservation written by Sharina Abdul Halim and Nor Azizah Ishak titled Examining Community Engagement in Heritage Conservation through Geopark Experiences from the Asia Pacific Region. Although the article is focused on the experiences of geoparks, nonetheless local community participation is basically essential for heritage conservation whether it be in geoparks, world heritage sites or even in biosphere reserves.

In their article, Sharina and Nor Azizah look at the experiences of geoparks from the Asia Pacific region regarding participation of the local communities for heritage conservation. Geopark concept promotes three main components, namely conservation of heritage resources, provision of tourism infrastructure and local socio-economic development. Strengthening local community engagement through active participation is pertinent to ensure success of geopark implementation. Engaging local community in heritage conservation collaboratively with other stakeholders is crucial as it has the potential to transform values, practices and overall behaviour towards sustainability. Nevertheless, how local community is 
engaged has been contested because oftentimes the term community engagement used in development process does not fully reflect the extent to which local community is actually able to participate. Analysis is based on reviews of secondary data resources and official geopark websites. Geopark-based heritage conservation activities are expressed in various ways, such as social interaction of festivals and exhibitions, as well as in natural resource management. In general, the main findings indicate that there is room for opportunities in geopark-based activities to encourage social learning among local community and stakeholders on heritage conservation. It is pertinent that the local community is engaged in activities that would strengthen its sense of belonging as local custodianship towards promoting sustainable resource utilisation in balancing conservation with development.

The broad perspective discussed in Sharina and Nor Azizah's article is followed by two articles on Melaka World Heritage Site (WHS). The first is by Rahimah Abdul Aziz entitled Heritage Conservation: Authenticity and Vulnerability of Living Heritage Sites in Melaka State. The second article is written by Ong Puay Liu entitled Community Involvement for Sustainable World Heritage Sites: The Melaka Case.

Rahimah's article discusses the issue of authenticity and vulnerability encountered by the stakeholders and custodians of the Melaka WHS in the face of modernisation and development processes. The focus of this article is the living heritage sites (LHS) in Melaka. The LHS seek to recreate historical settings to simulate past time periods, thus providing visitors a glimpse of what it would be like to live in the past. Such sites call for the participation and involvements of ethnic-specific groups to shape and preserve their cultural heritage and identity. Living heritage sites can also be regarded as a way for the community to seek relevance especially in a multi-cultural society. However, authenticity is among the major concerns of the living heritage sites as well as other factors that they encountered in the face of modernisation and development that subsequently contribute to their vulnerabilities. The discussion is based on the study of three living heritage sites in Melaka. The living heritage sites are Kampung Morten, Kampung Chetti and Kampung Portugis. In-depth semi-structured interviews were conducted with various key individuals of the three communities as well as focus group discussions with members of the community. The study shows that although there are concerns that need to be addressed, the informants believe that through the living heritage sites the community members are able to express their cultural identity, pride and knowledge to their younger members as well as share them with the society in general.

In her article Ong Puay Liu states that the sustainable protection of heritage is very important to the international community as a whole (UNESCO World Heritage Centre, 2015: 2). To ensure the success of heritage conservation, during the UNESCO-initiated conventions (UNESCO Convention for the Safeguarding 
of the Intangible Cultural Heritage 2003 and UNESCO World Heritage Centre's Operational Guidelines for the Implementation of the World Heritage Convention 2015), much emphasis was given on the participation of communities and individuals that create, maintain and transmit such heritage. However, the question is to what extent is the concept of a community-based heritage protection and conservation adopted by authorities in World Heritage Sites in their efforts to safeguard the heritage of outstanding universal value and sustain the status of their respective sites? Ong's article argues that for sustainable continuity as a World Heritage Site, local communities of World Heritage Sites should be regarded as the subject of development, and not as object of development. They should be one of the principal actors, and actively involved in decision-making that will impact their living conditions and life. To further elucidate this argument the author had chosen Melaka as a case study, focusing on the participation of the local communities in the planning and management of heritage protection and conservation of Melaka as a World Heritage Site. A series of consultations and focus group discussions were conducted with the various communities in 2013-2014. The research findings indicate that community participation in the planning and management process is minimal and that the local community is largely excluded from this process.

Moving on from Melaka WHS, the next two articles are based on experiences of geoparks within the context of heritage conservation. This segment starts with the article on Connecting the Legend and Scientific Case of Langkawi UNESCO Global Geopark penned by Tanot Unjah and Sharina Abdul Halim. The second article on Geopark is entitled Governance Networks for Effective Custodians' Participation in the Sustainability of Langkawi as a Geopark written by Geraldine K. L. Chan.

The article by Tanot and Sharina attempts to connect the scientific aspects of a geological landscape and the myth, legend and folklore in Langkawi UNESCO Global Geopark or referred to as geomythology. Langkawi's geological landscape comprises five key rock formations known as Machincang Formation, Setul Formation, Singa Formation, Chuping Formation and igneous rock of Gunung Raya. Each exposed rock diversity reacts differently to tectonic activity and weathering process caused by waves and surface run off water. These landscapes, with their distinctive rock diversity seem to hold within them the mysterious, connecting local communities with the landscapes, through myth and folklore. Among the wellknown "legendary" geosites within these landscapes are Gunung Machinchang, Gunung Raya, Belanga Pecah, Pulau Ular, Pulau Selang and Pulau Kentut (Pulau Intan since 2000), Pulau Dayang Bunting, Pulau Jong and Gua Cherita. They feature in the legend of the fight between Mat Chinchang and Mat Raya; the legend of the son of a Roman Emperor and a giant bird; and the tale of a pregnant maiden. Observations of these geological landscapes have shown that they form part of the local culture, and carry great significance to the area. Landscape descriptions from 
the geological or scientific perspective when integrated with cultural knowledge have revealed the intrinsic link between the geology and its people. Not only does this add great conservation value, it serves as a means to boost tourism that can in turn help facilitate local economic development of the area.

The following article focusing on heritage conservation in Langkawi Global Geopark is by Geraldine K. L. Chan. The article attempts to show that networks are essential and effective in custodians' participation in the sustainability of Langkawi as a geopark. Based on the findings from two empirical studies on effective governance networks for the success of Langkawi as a geopark, the article argues that effective custodian participation is best achieved through a proper governance network system whereby the networks are established between at least two or more organisational and non-organisational custodians irrespective of their social status, ethnicity, gender and wealth, and income levels. Specifically, the custodians should, more than before, come together to work together and establish networks in a transparent, accountable, responsible, fair, trustworthy and consistent manner. Effective participation for them would be in terms of shared norms of behaviour such as cooperation, assistance and influence. Furthermore, such effective participation is based on shared views, shared values, some other shared norms and other shared aspects guided to some extent by basic network principles such as reciprocity and mutuality. This implies that similarity or commonality is a key feature in social networks formation of the custodians. Trust is also present as a network element. Therefore, for Langkawi to sustain as a geopark in present and future times, effective participation from all custodians can be achieved through governance networks or social networks.

The four remaining articles address varied issues but that also relate to continuing legacies and heritage conservation. They are issues on revitalising the waning soul of Kampong Bharu, of laws and mandates regarding heritage conservation and of university students as custodians in heritage conservation enrichment. Halimaton Saadiah Hashim, Sarah Aziz and Nik Mohd Ruiz Razy write about Urban Revitalisation for a City's Soul: The Case of Kampong Bharu. According to the writers it is an accepted belief of the urban planning gurus that liveable and sustainable cities, neighbourhoods and communities are those that are with souls. The souls differ according to the communities' socio-cultural, economic, political and physical environments and perspectives. In short the soul of a city is in its inhabitants or people. This article presents findings from a study on the revitalisation of Kampong Bharu. Being only a conceptual study, the findings are only based on literature review, observations through walkabouts and drive-throughs, and interviews with custodians and major stakeholders. The article presents the results of the conceptual study: the concept of a city's soul in urban planning, the urban village concept, history and characteristics of Kampong Bharu the urban village, manifestations of its soul, key issues in revitalising 
Kampong Bharu i.e. custodians, mandates and institutional arrangement, heritageled development, and a brief assessment of actions in urban heritage conservation and revitalising Kampong Bharu's soul. The study concludes by supporting the move to revitalise Kampong Bharu and its soul. However the article recommends a deeper research to untangle the conundrum created by its legal and institutional arrangements; to establish a formal definition of Kampong Bharu's soul; develop a set of criteria for planning a heritage-led development; and catalogue the tangible and intangible Malay cultural elements in Kampong Bharu.

The article titled Engagement of Undergraduate Students as Custodians in Heritage Conservation Enrichment is written by Pue Giok Hun. According to the writer, one particular concern with regard heritage conservation in Malaysia is knowledge about minority ethnic groups with the potentials to be considered as regional heritage such as the various Peranakan communities in Malaysia. Hence, the writer feels that it is a race against time to have the communities' rich and invaluable culture documented for future preservation and conservation. Using the content analysis technique, the article is based on a survey of theses as a potential viable source of knowledge on a minority ethnic community in Malaysia with focus on Peranakan Chinese in Kelantan. Selected available theses pertaining to social aspects of the community that were written at the Bachelor degree level at Universiti Kebangsaan Malaysia (UKM) and Universiti Malaya (UM) from 1970s to 2010 s are analysed. Findings of the study suggest that theses can potentially serve as custodians to the untapped "treasure trove" of Malaysian heritage by preserving arcane information of the community at the grass-root level. Several theses written at postgraduate level even go beyond "potentials" after they were polished and published as books, subsequently significantly contributing to building and defining what we now know about the community and its heritage.

After looking at the issue of urban revitalisation of Kampong Bharu's soul, and that of documenting knowledge on minority ethnic communities in Malaysia, the following two articles focus on the issue relating to laws and mandates governing heritage conservation. Sarah Aziz and Siti Zuhaili Hasan's article on Enhancing Federal Government Mandates to Ensure Continuity of Heritage Legacies, contends that the responsibility to ensure a legacy is continued, particularly for cultural and natural heritage, often rests with the government agencies, armed with the necessary legislative mandates to safeguard and protect them. Thus, their article looks at the intricate relationship focusing on different Federal government mandate holders of cultural and natural heritage conservation, taking into account the federated system of government in place in Malaysia. The question addressed revolves on what needs to be safeguarded and how can it be properly contextualised, taking into account the complex nature of a heritage and the interactions between those who know, perhaps have "inherited" and have cared, with those who are tasked to guard. In addition, the roles of those who act 
as custodians are also looked into, and ways are explored as to how they could be spelt out towards enabling a collaborative arrangement, in order to ensure that existing mandates become complementary and mutually supportive. The article also briefly discusses a segment of the current Federal government arrangement, and challenges as well the opportunities ahead in Malaysia.

The last article in this special issue is written by Lee Jing and titled Exploring the Narrative of Heritage through the Eyes of the Law. The article explores the narrative of the normative landscape of heritage conservation and its progressive development. The writer opines that "heritage" is a difficult concept to define. Also, to determine what heritage "is" and to whom it is considered a "heritage", is a highly subjective, value-oriented exercise, contingent on the individual, groups and communities who in various ways, identify themselves with, and relate themselves to the heritage. The article adopts a discursive approach in interpreting the heritage discourse as codified in the relevant international legal instruments. An inquiry into the dynamic interpretation of "heritage" couched in the imperative to protect and to safeguard both tangible and intangible heritages are considered as important in supporting the efforts towards the conservation of heritage. This is because it will ultimately enable the leaving of a legacy that could be inherited by future generations.

\section{CONCLUSION}

All the articles compiled in this special issue deal in various ways with heritage conservation and how the engagement of the local custodians especially the local communities is essential in ensuring that the legacies are inherited by successive generations. This collection of articles not only contribute to the corpus of knowledge particularly on Malaysian sustainable heritage studies (natural and cultural), but also provide further insights on the subject of heritage conservation as well as on the roles that local custodians can play in ensuring continuing legacies. It is also hoped that the articles will help readers to further understand the importance of local community participation in heritage conservation as local knowledge is privy of those who are actually experiencing and practising them at the grass roots level.

\section{ACKNOWLEDGEMENTS}

This special issue draws its strength from the contributors, whose efforts are very much appreciated. The insights and inputs put forth by the reviewers are invaluable and had added dimensions which helped to further strengthen the articles. The 
contributors would also like to express their gratitude to UKM that had made this publication possible through the various research grants. Last but not least, this publication would not have been possible without the support of the Editorin-Chief of Kajian Malaysia, which has resulted in this special edition that went through independent reviews and editorial process.

\section{REFERENCES}

Balmford, A. and R. M. Cowling. 2006. Fusion or failure? The future of conservation biology. Conservation Biology 20: 692-695.

Daily, G. C. and P. R. Ehrlich. 1999. Managing earth's ecosystems: An interdisciplinary challenge. Ecosystems 2: 277-280.

Government of Malaysia. 2005. National Heritage Act 2005. Malaysia: Government of Malaysia.

International Council on Monuments and Sites (ICOMOS). 1987. Charter for the conservation of historic towns and urban areas. http://www.icomos.org/en/179articles-en-francais/ressources/charters-and-standards/159-charter-for-theconservation-of-historic-towns-and-urban-areas (accessed 19 December 2016).

Jopela, A. 2011. Traditional custodianship: A useful framework for heritage management in Southern Africa. Conservation and Management of Archaeological Sites 13(2-3): $103-122$.

Reyers, B., D. J. Roux, R. M. Cowling, A. E. Ginsburg, J. L. Nel and P. O'Farell. 2010. Conservation planning as a transdisciplinary process. Conservation Biology 24(4): 957-965. https://doi.org/10.1111/j.1523-1739.2010.01497.x

Trinidad, R. 2015. Heritage at risk: The authority and autonomy of a dominant preservation framework. In Heritage keywords: Rhetoric and re-description in cultural heritage, eds. K. Samuels and T. Rico, 147-162. United States: University Press of Colorado. http://www.jstor.org/stable/j.ctt16nzfgg.15. (accessed 19 December 2016).

United Nations Educational, Scientific and Cultural Organization (UNESCO). n.d. Identifying and inventorying intangible cultural heritage. https://ich.unesco.org/ doc/src/01856-EN.pdf. (accessed 10 December 2016).

UNESCO World Heritage Centre. 2015. Operational guidelines for the implementation of the World Heritage Convention (WHC.13/01). Paris: UNESCO World Heritage Centre. http://whc.unesco.org/en/guidelines/ (accessed 12 June 2016). 